\title{
Tuberculosis: A Time for Decision
}

\author{
- By thOMAS PARRAN, M.D., Dr.P.H.
}

\begin{abstract}
A S THE HENRY PHIPPS INSTITUTE A celebrates its first half century of achievement, it is useful to undertake an appraisal of where we stand today in the battle against tuberculosis, and to attempt to draft the strategy for finishing the job. I realize the futility of hoping to contribute original ideas at this time for decision. All I presume to offer is a candid camera shot of the forest in which the tuberculosis experts have been doing excellent work among the trees.

That you may forbear as I attempt this, I quote Laennec, who wrote to his cousin : "Do not fear to repeat what has already been said. Men need these things dinned into their ears many times and from all sides. The first version makes them pick up their ears, the second registers, and the third enters" (1).
\end{abstract}

Dr. Parran, dean of the Graduate School of Public Health of the University of Pittsburgh, was Surgeon General of the Public Health Service from 1936 to 1948. In an article entitled, "No Defense For Any of Us," which appeared in the April 1938 issue of Survey Graphic, he suggested methods which could be followed in setting up a program for national control of tuberculosis, since many of the techniques used in the program for the control of venereal diseases, which already had been started, could be applied to tuberculosis control. During the early part of World War II, he supported the Public Health Service's experimental work on the use of small films in $X$-ray examinations. This work led to trials of the films on a demonstration basis. Soon afterward, in 1944, the national tuberculosis control program was authorized and began operation.

Vol. 68, No. 10, October 1953

\section{Early Approaches}

Prior to 1900 , public health measures were largely punitive. Quarantine, it was assumed, would erect safe barriers to the spread of epidemic disease. Later, specific immunization, long effective in the control of smallpox, was believed to be the method of fulfilling Pasteur's prophecy that "infectious disease would be banished from the earth."

Concurrently, the sanitary engineer played a major role in improving the human environment by the purification of public water supplies, the pasteurization of milk and other dairy products, and the draining or neutralizing of mosquito breeding grounds. He also initiated more sanitary methods in the handling of food, while the chemists taught processors how to preserve it safely. Refrigeration made possible a diet including fruits and green vegetables at all seasons. Nutritionists began nailing down some scientific facts as to what constitutes a good diet-they have no more finished their task than have the chemotherapists-and dietitians by the thousands emerged in a new profession to demonstrate these facts in many situations ranging from the factory lunchroom to the high school class of future housewives.

The Phipps Institute was born at one of the most exciting periods in the whole history of public health and preventive medicine. American living standards were being sharply raised and health standards along with them. There is no doubt that each set of conditions interacted upon the others and that hundreds of thousands of persons susceptible to tuberculosis yet not acquiring the disease were the beneficiaries. 
Those who have devoted their lives to the control of tuberculosis have had valid cause for pride as they have watched the great downward curve of mortality from this disease. When the Phipps Institute was established 50 years ago, the "Captain of the Men of Death" was killing Americans in the most productive period of their lives at a rate more than 10 times greater than today. Today the world is convinced that tuberculosis is conquerableconvinced by demonstration rather than exhortation. Great minds, great hearts, great leadership, and great moneys have been rallied to this cause. Now, in 1953, the target has become measurable. The goal of eradication in this country and in our time is now attainableat least to the optimist. And nobody but an optimist has any business in public health at all, in any of its branches.

\section{Contributions by Nonmedical Men}

The golden anniversary of the Phipps Institute represents, to my mind, an important factor in the progress of public health, but one often forgotten when the laurel wreaths are distributed and the accolades bestowed. It illustrates the great part played by laymen of vision, generosity, and courage who have contributed as greatly to the control of tuberculosis as has the brilliant work of scientists.

Many of the names are forgotten. One needs to dig below the surface in the history of this Institute, for example, to learn that when Henry Phipps in 1901 sought advice as to useful channels for his charitable endeavors, his close friend Samuel P. Harbison, of Pittsburgh, referred him to Francis J. Torrance, then a member and later president of the Pennsylvania State Commission of Public Charities. And in due course the Phipps Institute was born into the world of scientific aspiration. No matter how substantial its support in later years and in years to come from other grants and benefactions, we must never forget that its origin was due to the advice and encouragement of practical businessmen who had the vision to look beyond the obvious and the immediate.

Administrative leadership is also indispensable. I know of no single person who contributed more to tuberculosis control, for ex- ample, than Homer Folks, for many years secretary of the State Charities Aid Association of New York. His great gift of leadership, his capacity for organization, and his eloquent persuasiveness, along with his incorruptibility and fine intelligence, would have made him a success in any business or profession. He chose to devote his talents to the public welfare in general and to tuberculosis control in particular, for the benefit of the people of the State of New York. With Dr. Hermann Biggs, New York's first great health commissioner, to steer a steady scientific course and with Homer Folks

50 Years of Tuberculosis

\section{"Study, Treatment, and Prevention"}

The past half century has been a dynamic period in the attack on tuberculosis a time of high hopes sometimes realized, sometimes dashed, but withal a time of steady progress in the development of the basic and applied knowledge essential to the eventual conquest of the disease.

Spanning this period and contributing importantly to the record of achievement is the Henry Phipps Institute for the Study, Treatment, and Prevention of Tuberculosis. It was founded in 1903 by the Pittsburgh industrialist Henry Phipps, whose interest in tuberculosis was stimulated by Dr. Lawrence F. Flick of Philadelphia, one of the founders of the National Tuberculosis Association. In 1909 the Institute became a part of the University of Pennsylvania.

In February of 1953 the Institute celebrated its golden jubilee, asking leaders in the "study, treatment, and prevention of tuberculosis" to share their appraisal of our present status and future prospects.

The authors and Dr. Esmond R. Long, director of the Henry Phipps Institute and director of medical research of the National Tuberculosis Association, have made these papers available to Public Health Reports in advance of their appearance in a commemorative volume. The major portion of Dr. Parran's discussion of the prevention of tuberculosis appears here, followed by a condensation of Dr. J. Burns Amberson's remarks on treatment.

\section{-The Editors}


to educate the people and their legislative representatives, the Empire State got off to a head start in public health and in tuberculosis control.

As other examples of nonmedical statesmen in public health, let me cite Frederick T. Gates and Wickliffe Rose, who guided the Rockefeller philanthropies which promoted medical education, added so much to our knowledge of preventable disease, and demonstrated so early the practicability of applying that knowledge to human need throughout the world. These are but a few among the many lay workers who have made possible the near victory in tuberculosis control and the almost complete victory against other and more vulnerable ancient plagues. Whatever our plans for the next half century, if they are to be successful, they must depend even more than in the past on citizens such as these.

Motivated in part by what Newsholm calls "the sentiment against suffering" and in part by the instinctive wisdom inherent in groups of good citizens who care profoundly and who will work devotedly for a cause outside and beyond their personal advancement, these men set forth zealously with the twin weapons of faith and hope. They had faith in our form of government, which will back with tax support measures for the welfare of the people after their authenticity has been demonstrated by voluntary pioneering. They had faith in the capacity of the average citizen to learn-to change his personal habits, if need be, in his own interest and that of his fellow citizen. They had hope that bed rest, fresh air, sunshine, and good food would help the victims of tuberculosis; that less crowding in filthy slums would lessen the spread of infection; that bovine tuberculosis could be eliminated.

Sociologists tell us how well-nigh impossible it is that people might change their habits without any specific promise that whatever they might do or might not do would save them from tuberculosis. Nevertheless, the people were motivated to action; a vast number were persuaded to do certain things and to refrain from doing others. All this, to my mind, entirely justifies the statement in the recent report of the President's Commission on the Health Needs of the Nation, "The individual effort of an in- formed person will do more for his health and that of his family than all the things which can be done for them." You will note particularly the adjective "informed."

\section{Current Status}

Because the gains in the fight against tuberculosis have been substantial, we can accept rather cheerfully the fact that Pasteur was altogether too optimistic in his opinion that infectious disease could be banished from the earth and that Allen Krause in forecasting that the trend of tuberculosis rate would bring it to zero in 1935 was quite wrong (2). Tuberculosis we still have with us, but it is in manageable dimensions, at least as far as the Western World is concerned. Many persons now forecast that tuberculosis may become a minor cause of death in Western Europe, in North America, and in Australia before we know the reasons for this event. That would be good for humanity but a black eye for science.

By any scale of values, however, the 90-percent reduction in mortality rates in this country from 194 per 100,000 population in 1900 to less than 20 in 1951 is an outstanding performance. But there must be no complacency in our view of the tuberculosis that remains among us. It is not the time for a change in the energy and relentlessness with which the disease has been attacked. National averages are misleading. Tuberculosis mortality now is $31 / 2$ times as hign in the nonwhite population as among white citizens. Iowa and Minnesota may have rates of less than 10 per 100,000, but Alaska and Puerto Rico have rates 6 to 10 times the national average.

Even though statisticians believe that 1952 figures will show it to be ninth among the causes of mortality, and although it now accounts for only 2 percent of deaths in the country as a whole, tuberculosis is still a leading cause of death among young adults. In monetary terms, national efforts to control this disease are costing the American people more than $\$ 350$ million a year-a figure which does not take into account the cost and depreciation of hospital buildings or the training of professional personnel (3). If we try to estimate the loss in family incomes when the wage earner is separated from 
his family for sanatorium care over long periods, and the fact that even though his life may be saved and his disease arrested he dares not go back to hard physical labor, the cost totals become astronomical. If one attempts to estimate the cost to the community of the broken homes so often resulting from tuberculosis either of father or mother, we would unhappily agree that tuberculosis still stands close to the top as a social tragedy, possibly exceeded only by mental disease.

\section{Factors Affecting the Decline}

Let us now consider briefly some of the reasons for the winning tide of battle thus far. We are faced at once with the paradoxical situation that not even the greatest living experts will make more than a cautious and qualified guess as to which of many relevant factors have had the greatest impact or what relative therapeutic or preventive weight may be given to any of them. A single exception to this generality is the epidemiological platitude that wherever the chain of infection is brokenwhenever an early case of tuberculosis is taken out of the family, social, or business environment- $x$ number of new cases do not develop. This single, simple fact may well be the keystone of the arch for the building of future programs.

Most experts are agreed that medical science alone cannot take major credit for the decline in tuberculosis rates, since the decline began long before control programs were initiated and before there were any scientific bases for such programs. For example, it has been estimated that the mortality rate in 1830 for the combined populations of Boston, New York, and Philadelphia was approximately 400 per 100,000 population; by 1900, this rate had dropped to approximately 250 in these three cities and to 204 in the United States as a whole.

As far back as 1937, when the mortality rate was far higher than today, Wade Hampton Frost, formerly of the Public Health Service and then of the Johns Hopkins University School of Hygiene and Public Health, expressed his belief that in this country we already had reached the stage at which the biological balance is against the survival of the tubercle bacillus. He felt that even though measures taken up to that date to limit the spread of the bacillus in our environment were insufficient to prevent the infection of the great majority, such measures might still have great effect.

Another consideration, Frost thought, is the fact of "conditions limiting the propagation of the tubercle bacillus, which are: $(a)$ that in order to escape from its host it must cause a lesion which breaks through the surface-in general, an extensive lesion which severely damages the host-and (b) that it succeeds in producing such a lesion in only a limited number of infected persons."

Various other pathogens of man are subject to one or another of these conditions, but none to both. The combination of these two limiting conditions constitutes the peculiarity of the tubercle bacillus which makes it more amenable to control by case isolation than are such diseases as diphtheria, scarlet fever, or measles. Consequently, Frost concluded: "Although tubercle bacilli multiply within the body, in a great many cases they do not escape to reach other hosts. Logically, therefore, for the eventual eradication of tuberculosis it is not necessary to set ourselves the impossible goal of immediate and complete prevention of all transmission. It is necessary that the rate of transmission be held permanently below the level at which a given number of infection-spreading cases succeed in maintaining themselves" (4).

This epidemiological prognosis should spur us to find more hidden cases and isolate them more swiftly from their susceptible associates. It encourages us also, in 1953, to believe that the biological balance is increasingly on our side.

\section{Elements of Uncertainty}

Nor should we disregard the elements of uncertainty which Frost pointed out, "among them, uncertainty as to the stability of our civilization." In the atomic age that has been thrust upon us since his death, we are all grimly aware that tuberculosis control, along with every other good thing our western civilization has evolved for and through its citizens, may be discarded in the event of another global war. 
But assuming that our civilization stands, and assuming a continuation and improvement of environmental control, Frost saw only two forces which singly or together might check or reverse the downward trend. They were (a) a decrease in human resistance to the disease and $(b)$ some fundamental change in the virulence of the tubercle bacillus, the specific properties of which, as he pointed out, have changed little in modern times.

As to the first of these possibilities, it might be noted that an increase in racial resistance over the centuries may be of some importance in "tuberculized" civilizations, but it does not explain the recent precipitous fall. Conversely, the low racial resistance among populations rarely exposed to infection is acknowledged. But since we assume that in the future these populations will not have similar gross repeated exposures, this fact is not of importance.

\section{Developments Since 1937}

It has been said that the level of tuberculosis mortality is a sensitive index of a complex variety of environmental factors. Since Frost made his carefully calculated predictions in 1937, a number of things have occurred in this country to affect that index. It is not possible to list these things in order of importance for, in fact, we do not as yet know with any degree of accuracy what has contributed most to the decline in the tuberculosis rate. Nevertheless, it is reasonable to assume, on the basis of experience, that each in some degree has weighted the scales more heavily against the tubercle bacillus.

1. Living standards, including standards of nutrition, have steadily improved; levels of education have risen; hours of work have lessened; general public health measures have been broadened and intensified.

2. As a result of increasingly intensive case finding, the number of newly discovered cases reached a peak of 137,006 in 1948; since then there has been a slight decline, year by year, to 118,491 new cases in 1951. Mass radiography of whole populations has become economically feasible and is being utilized for the benefit of about 14 million American citizens each year.

3. Chemotherapeutic agents have proved helpful and may point the way toward a specific. Surgical procedures have been improved and are more widely used in appropriate cases to lessen the spread of infection and to prolong life.

4. The National Tuberculosis Act of 1944 charted a Federal policy and program for control of the disease, with States and research agencies cooperating, and authorized support for more extensive and more unified efforts.

5. A worldwide attack upon tuberculosis has been organized; the value of the BCG vaccination has been confirmed-though it is far from a complete answer for the prevention of tuberculosis-and it is being used on a broad scale internationally, especially in the war-torn and underdeveloped countries.

\section{Quo Vadis?}

At this point it is relevant to inquire, quo vadis? I agree with Dubos that progress does not necessarily consist of doing more and more of what has proved profitable in the past. Research is certainly needed. Even though the results may prove only that we are on the right track, research is needed to validate our going forward faster in the familiar channels.

But we cannot mark time waiting for the result of inquiries. In my opinion, these are some of the things we must go on doing at a brisk tempo, concurrently with a diversity of research :

1. Hospital beds more wisely utilized for the patients with active disease are the crux of the problem. Some waiting lists for such beds now are so long that the discovery of new cases in the absence of the means of relieving them perhaps adds to the sense of frustration.

2. More and better trained personnel are of equal importance with the provision of hospital beds. In some sanatoriums whole wings are closed for lack of professional staff. We need to recruit actively nurses, doctors, and technical personnel of all descriptions. We need to recruit an increasingly better type of student, and to make sure these are offered as good a professional opportunity in the care of the tuberculous patient as in any other area of medicine and public health.

3. Even though the disease may be eradicated 
without better vaccines and drugs-merely by integrating biological wisdom with social technology in the management of everyday lifethe search for the vaccine or for the drug might, in the long run, be simpler. A better vaccine or the new cure may be found. BCG and some new chemicals may be short steps in the right direction, or an entirely new direction may be indicated. Whatever the answer, the search must go on.

\section{Exploration Needed}

So far, I have been urging that we do more and that we do better some of the things already being done. Nevertheless, there are several areas in which we know very little about the potentialities for tuberculosis control and where exploration appears to be clearly called for.

For example, every student of tuberculosis is aware of the varying emphasis on diets over the years. Yet what, precisely, do we know about what types of food deficiency are or may be critical in their impact upon the patient? I am convinced only that during both world wars the lack of food was correlated with increased mortality from tuberculosis and that relief from a starvation diet was followed by a prompt reduction in mortality.

We have made general assumptions as to the relationship between "poor living conditions" and tuberculosis. Actually, we know nothing about it on the basis of scientific study.

We believe that exhausting physical work adversely affects resistance, but how we do not know. Does this factor or the working environment, or do both factors, account for the relatively higher death rate among older males? Springett maintains that despite the present form of the tuberculosis mortality curve, there has never yet been a group of men who experienced a greater mortality at ages over 45 years than their contemporaries experienced at young adult ages (5). Frost and others earlier reached the same conclusion, as the age "cohorts" of mortality were analyzed. From this evidence, can we conclude that tuberculosis deaths, in later life are usually, though not always, the result of disease acquired many years earlier? In fact, it appears that the lifetime experience of any generation can be pre- dicted. from its level of mortality in the first years of life. Available evidence regarding exogenous and endogenous infections conflicts.

Even though it is not possible to change the totality of what we consider an adverse environment-in other words, we are not yet able to abolish poverty-may it not be found by careful investigation that some one factor predominates? Having found it, might it not be possible to ameliorate that one factor?

Research of this type is difficult and costly. It involves the skills of the social scientists integrated with the skills of public health and clinical scientists. The Graduate School of Public Health of the University of Pittsburgh is particularly interested in this type of study and is undertaking it in reference to certain other chronic diseases.

The Phipps Institute has pioneered in the fields of immunity and susceptibility in tuberculosis, and its experts would be the first to insist that the surface has hardly been scratched. Such work should continue, even if by some happy accident the perfect vaccine were to be discovered tomorrow, because of its contribution to our understanding of other disease processes.

We know little about the ways in which emotional stress affects resistance. That it does seems possible from the drop of the mortality curve in Japan, Germany, and Austria after the war had ended but before there were available good food, decent housing, or other factors, which in the United States we have considered basic for tuberculosis control.

Is the well-known tendency of tuberculosis to reactivate related to tension or emotional stress? Is this a factor among the infectious patients who leave the sanatorium against advice? Since 25 percent of our tuberculous veterans and an even larger percentage of civilian patients fall into this latter category, it would seem that we need scientists specializing in human behavior to integrate their skills with those of the tuberculosis epidemiologists and clinicians.

\section{Expansion of Present Activities}

Sanatorium care is the largest single debit entry in the United States control program. In 
a recent review, Dr. Long very wisely suggests making more beds available for more patients by greater cooperation with the practicing physician, especially for those patients who have responded so well to hospital care and indoctrination that they may be sent home under proper medical supervision and chemotherapy (3).

This is sound in principle for several reasons: It should reduce the total cost of care, return the patient earlier to his family, and increase the interest and participation of more physicians in tuberculosis control. This last point is important, since private physicians now report only 15 percent of the new cases. Moreover, this suggestion is strengthened by the precedent of syphilis. A decade ago its treatment was practically a health department monopoly; today the private physician has taken over a very large proportion of it.

In addition to the mass $X$-rays, which serve as a dragnet gathering in many unsuspected cases, hospitals and clinics should be required to make a chest X-ray routinely upon every person entering for any disease condition. In view of the fact that the care of each tuberculosis patient costs, on the average, about $\$ 15,000$, every institution of diagnosis or healing should utilize every opportunity to identify another link in the chain of infection.

From my own experience in dealing with syphilis and other communicable diseases, I would suggest a much greater use of the epidemiological method. This is particularly practical in this country during the present period of transition, when a large part of the population is not exposed to tuberculosis until adult life and many not even then.

In 1900 , by contrast, our environment was literally saturated with the tubercle bacillus, like fog in a valley. Not so today, when there is evidence to show that tuberculosis is kept alive by a series of local epidemics. Intensive epidemiological study can ferret out the source, the contacts, and the secondary cases not only in households but also in schools, factories, restaurants, business offices, and through the routine X-ray of all patients of hospitals and clinics. Here are opportunities to break the chain of infection and save the maximum of human suffering and economic loss with the minimum of effort and expense. They should be explored more fully.

\section{Steps Toward Success}

It is highly commendable to have developed a more or less standard control program for tuberculosis, or any other disease entity. It will, however, become static and steadily less effective unless we constantly evaluate each part of it. We need to search endlessly for more facts, for new approaches. Even though our battle against tuberculosis has gone well, we are still at the frontiers of knowledge. I suggest, in short, more pinpointing of the predisposing and precipitating factors of the disease and their mechanisms of action, changing our emphasis as new truths become known, adding or subtracting one or another element in the program as knowledge grows and the disease declines.

"To combat consumption successfully," wrote Knopf of Philadelphia in 1901, "requires the combined action of a wise government, welltrained physicians, and an intelligent people." I doubt that his prescription for success can be bettered today. In this time we have set for decision, we have nothing to fear except complacency and dogmatism, nothing to avoid except inflexibility or inaction, and everything to hope for in a greater half century than the one just past.

\section{REFERENCES}

(1) Dubos, R., and Dubos, J : The great white plague. Boston, Little, Brown \& Co., 1952.

(2) Rich, A. R.: The pathogenesis of tuberculosis. Ed. 2. Springfield, Ill., Charles C. Thomas, 1951.

(3) Long, E. R.: The problems of tuberculosis control. Editorial. Ann. Int. Med. 37: 1095-1099 (1952).

(4) Frost, W. H.: Risk of persons in familial contact with pulmonary tuberulosis. Am. J. Pub. Health 23: 426-432 (1933).

(5) Springett, V. H.: An interpretation of statistical trends in tuberculosis. Lancet 1: 575-580 (1952). 